\title{
Term Broad Ligament Pregnancy with a Healthy Newborn
}

\author{
Md. Akbar Hossain *1, Farida Begum ${ }^{2}$, Sultana Jahan ${ }^{3}$, Israt Sharmin ${ }^{4}$, Nazifatur Raihana ${ }^{5}$
}

Abstract

Introduction: Broad ligament pregnancy also known as inter ligamentous pregnancy is a rare type of ectopic pregnancy. It is one type of secondary abdominal pregnancy. Although ultrasonography is usually helpful in making the diagnosis but it is mostly established during laparotomy. Very few successful live births have been reported in this condition, where such pregnancies reached term and with live birth of a baby. Case Report: A case of 30 year old 2nd gravida of 38 weeks gestation with lower abdominal pain for 20 hours was admitted into Sher-E-Bangla Medical College Hospital, Barishal; Bangladesh. She was suggested for caesarean section as the ultrasonogram revealed transverse lie with complete placenta praevia. Intraoperative diagnosis of right sided broad ligament pregnancy was made and an incision was given on the anterior leaf of the broad ligament and a male live fetus was extracted. Post operative period was uneventful. Both mother and baby were discharged on seventh postoperative day in good health condition. Discussion: Broad ligament pregnancy usually results from rupture of tubal pregnancy through the tubal serosa and the mesosalpinx, with secondary implantation of trophoblast between the leaves of broad ligament. Incidence of broad ligament pregnancy is reported as 1 in 300 ectopic pregnancies. The prognosis is poor with the risk of dying from an abdominal pregnancy is 7.7 times higher than from other forms of ectopic pregnancy and often results from a delay in diagnosis. Trans-vaginal rather than transabdominal ultrasonography is superior in the evaluation of ectopic pregnancy. If there is no intrauterine pregnancy on ultrasonography and the ectopic sac is beside the lower part of the uterus a strong suspicion of broad ligament ectopic should be considered. Very rarely such pregnancy may reach up to term. Bleeding from placental implantation site is the most life-threatening complication during laparotomy. Conclusion: Abdominal pregnancy with resultant healthy newborn is very rare. High level of suspicion, careful clinical and ultrasound examinations are the routine means of diagnosis. Bleeding is the single most important life-threatening complication for the mother. Early diagnosis and proper management are vital in order to decrease maternal morbidity.

Keywords: Broad ligament pregnancy, Ectopic pregnancy, Laparotomy, Salpingo-oophorectomy, Ultrasonography.

Number of Figures: 02; Number of References: 26; Number of Correspondences: 05

* 1. Corresponding Author: Dr. Md. Akbar Hossain

Assistant Professor

Department of Gynaecology and Obstetrics

Sher-E-Bangla Medical College, Barishal, Bangladesh.

Email: dmahob@gmail.com

Mobile No: +8801711119803

2. Dr. Farida Begum

Senior Consultant

Department of Gynaecology and Obstetrics

Sher-E-Bangla Medical College, Barishal, Bangladesh.

3. Dr. Sultana Jahan

Indoor Medical Officer

Department of Gynaecology and Obstetrics

Sher-E-Bangla Medical College Hospital, Barishal, Bangladesh.

4. Dr. Israt Sharmin

Assistant Registrar

Department of Gynaecology and Obstetrics

Sher-E-Bangla Medical College Hospital, Barishal, Bangladesh.

\section{Dr. Nazifatur Raihana}

Honorary Medical Officer

Department of Gynaecology and Obstetrics

Sher-E-Bangla Medical College Hospital, Barishal, Bangladesh.

\section{Introduction}

Ectopic pregnancy represents about 1 and $2 \%$ of that of live births in developed countries, though it is as high as $4 \%$ in pregnancies involving assisted reproductive technology with 93 to $97 \%$ occurring in the fallopian tube $^{1,2}$. Abdominal pregnancies represent just about $1 \%$ of ectopic pregnancies and the maternal mortality rate has been reported to be as high as $20 \%{ }^{3,4}$. The incidence of abdominal pregnancy differs in various publications and ranges between 1:10000 pregnancies and 1:30,000 pregnancies, and being most prevalent in developing countries with limited resources and limited diagnostic facilities ${ }^{5}$. Albucasis (936-1013), the Arab Muslim physician is credited with first recognizing abdominal pregnancy which was apparently unknown to Greek and Roman physicians and was not mentioned in the writings of Hippocrates; Jacopo Berengario da Carpi (1460-1530) the Italian physician is credited with the first detailed anatomical description of abdominal pregnancy ${ }^{6}$. It may occur in any part of the abdomen but is common in pouch of Douglas and is rare in broad ligament ${ }^{7}$. Ectopic pregnancy in the broad ligament is a retroperitoneal abdominal pregnancy, in which the foetus or gestational sac develop within the leaves of the broad ligament ${ }^{8}$. It usually results from fallopian tube rupture nearingmesosalpinx and then the pregnancy continuing within the leaves of broad ligaments. It has vivid presentations, may present as lower abdominal 
pain, an abnormal lie, placental insufficiency, foetal death or acute abdomen due to rupture of gestational sac with haemorrhage into the peritoneal cavity. In literature a few cases have been reported where such pregnancies reached term and even with live birth of a baby $9,10,11,12$.

Here a case of advanced broad ligament pregnancy has been described where clinical as well ultrasonography did not help to diagnose it and was only detect it intra-operatively.

\section{Case Report}

A case of 30 year old 2 nd gravida, para $0+1$ of 38 weeks gestation with lower abdominal pain for 20 hours was admitted into Sher-E-Bangla Medical College Hospital, Barishal; Bangladesh. Her early pregnancy was uneventful but she had irregular menstrual cycles prior to her pregnancy and was not sure of her last date of menstruation. The ultrasound examination had not been performed in the first trimester. On examination, her vital signs were stable and tenderness was present in the right iliac fossa and right lumbar region. The height of the uterus corresponded to 36 weeks gestation. Amniotic fluid was seemed to be normal and foetal heart sound was 136 beats / min. An ultrasound was performed, which confirmed a live term foetus of 38 weeks, in transverse lie with complete placenta praevia. Caesarean section was planned in view of the transverse lie with placenta praevia.

With all aseptic precaution abdomen was opened with Pfannenstiel incision. At a glance the lower uterine segment was not detected. After careful examination a diagnosis of right sided broad ligament pregnancy was made and an incision was given on the anterior leaf of the broad ligament and a male live fetus was extracted. Placenta was found on the posterior leaf of the broad ligament and; the fallopian tube and ovary were densely adhering with the placental membranes. The placenta was removed without any undue haemorrhage and right sided salpingo-oophorectomy was done to remove the adherent fallopian tube and ovary. Uterus was lying medial to the sac and was around twelve weeks in size. A unit of compatible blood was transfused intraoperatively. Post operative period was uneventful. Both mother and baby were discharged on seventh postoperative day in good health condition.

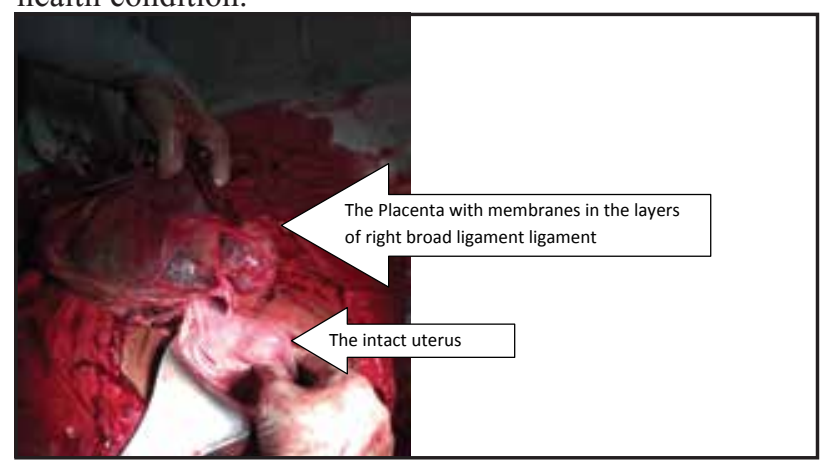

Fig-1: The intact uterus and the placenta with membranes in the layers of right broad ligament of this patient. (Photo Credit- Dr. Sultana Jahan).

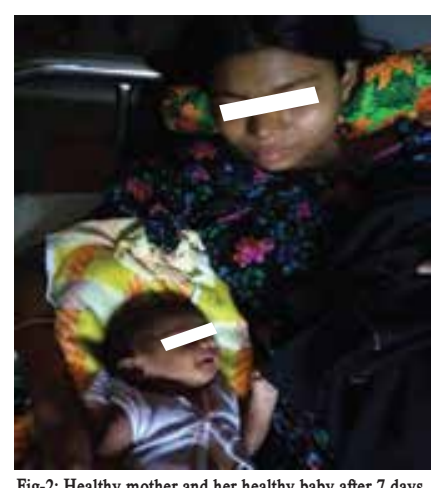

Fig-2: Healthy mother and her healthy baby after 7 days. (Photo Credit- Dr. Sultana Jahan).

\section{Discussion}

Broad ligament pregnancy is an extremely rare form of ectopic abdominal pregnancy. Incidence is reported as 1 in 300 ectopic pregnancies ${ }^{13}$. A broad ligament pregnancy usually results from trophoblastic penetration of tubal pregnancy through the tubal serosa and into the mesosalpinx, with secondary implantation between the leaves of broad ligament. Rare types of secondary abdominal pregnancies can occur after spontaneous separation of an old caesarean section scar, after uterine perforation during a therapeutic or elective abortion, and after subtotal or total hysterectomy ${ }^{14}$. The prognosis is poor, with an estimated maternal mortality rate of 5.1 per 1,000 cases $^{15}$. The risk of dying from an abdominal pregnancy is 7.7 times higher than from other forms of ectopic pregnancy ${ }^{16}$. The high rate of morbidity and mortality from abdominal pregnancy often results from a delay in diagnosis.

Pelvic inflammatory disease, use of intrauterine devices, use of progesterone only pills, a previous history of ectopic pregnancy, abdominal tuberculosis and endometriosis are the various risk factors involved ${ }^{17}$.

Presentation of abdominal pregnancy can be varied from mild abdominal discomfort, small amount of vaginal bleeding, placental insufficiency leading to fetal demise to catastrophic internal haemorrhage, manifesting with acute abdomen and shock. Careful clinical examination and observation may help in diagnosing the pregnancy.

Diagnosis of advanced abdominal pregnancy requires a high index of suspicion. History and physical examination are often inconclusive. In spite of considerable improvement in technical abilities, absolute diagnosis by ultrasound is missed in half of the cases ${ }^{18,19}$. The following features should alert the sonographer: abnormal relationship among the fetus, placenta, amniotic fluid and uterus, fetal skull or small parts overlying the maternal spine on lateral projection, fetal malpresentation especially transverse $1 \mathrm{e}^{20}$. Case reports by Sharma and Rudra had correctly diagnosed the abdominal pregnancy by ultrasound ${ }^{21}$. But in this case diagnosis was missed by ultrasounds rather it was diagnosed intra-operatively. Other cases have also been reported in the literature in which diagnosis of abdominal pregnancy was made intraoperatively ${ }^{22}$. Trans-vaginal ultrasonography is superior in the evaluation of ectopic pregnancy since it allows a better view of the adnexa and uterine cavity. If there is no intrauterine pregnancy on ultrasonography and the ectopic sac is beside the lower part of the uterus a strong suspicion of broad ligament ectopic should be considered. MRI is the better diagnostic tool as it also guides regarding the extent of peritoneal involvement and surgical planning. 
Exploratory laparotomy is the gold standard in the management of broad ligament pregnancy. However in haemodynamically stable patients, removal of small broad ligament pregnancies can be considered laparoscopical$1 y^{23}$. Very rarely such pregnancy may reach up to term and delivered by laparotomy along with excision of placenta which may be adherent to surrounding structures like intestines mesentery etc. posing difficulty in achieving haemostasis ${ }^{21}$.

Bleeding from placental implantation site is the most life-threatening complication during laparotomy. The decision to remove the placenta or not can be a determining factor for the survival or otherwise of the woman and this decision is subject to the surgeon's expertise and the particular case in question. It is generally recommended to leave the placenta in situ and make a follow up with human chorionic gonadotropin levels ${ }^{24}$. In this case there was significant bleeding from some detached portions of the placenta that prompted removal of these portions to secure haemostasis. The patient was transfused with one unit of blood during the operation. For the newborn, it is very important to rule out congenital malformations. There are reports of foetal malformations as high as $40 \%$ associated with abdominal pregnancies and only $50 \%$ of these babies survive up to one week post delivery ${ }^{25}, 26$. In this case the new born baby was normal in morphological appearances and reflexes on examination.

\section{Conclusion}

Diagnosis of abdominal pregnancy can be missed during antenatal care but high index of suspicion in cases of abnormal lie, displaced cervix and failed induction of labor can help in diagnosis of abdominal pregnancy. Expertly performed and interpreted ultrasonography may be the definitive diagnostic technique. Early diagnosis is the only key to reduce high incidence of maternal mortality.

Conflict of Interests: None.

\section{Acknowledgement}

It is our great pleasure to acknowledge with heartiest gratitude the constant encouragement and guidance given us by Director and Ethical Committee, Sher-E-Bangla Medical College \& Hospital, Barishal and the patient which paved our way and acted as source of inspiration in preparing this case report.

\section{References}

1. Kirk E, Bottomley C, Bourne T. Diagnosing ectopic pregnancy and current concepts in the management of pregnancy of unknown location. Human Reproduction Update. 2014; 20 (2): 250-61.

https://doi.org/10.1093/humupd/dmt047

PMid:24101604

2. Crochet JR, Bastian LA, Chireau MV. Does this woman have an ectopic pregnancy?: the rational clinical examination systematic review. JAMA. 2013; 309 (16): 1722-9.

https://doi.org/10.1001/jama.2013.3914

PMid:23613077
3. Ludwig M, Kaisi M, Bauer O, Diedrich K. The forgotten child: a case of heterotropic, intraabdominal and intrauterine pregnancy carried to term. Hum Reprod. 1999; 14: $1372-4$

https://doi.org/10.1093/humrep/14.5.1372

PMid:10325296

4. Alto WA. Abdominal pregnancy. Am Fam Physicain. 1990; 41: 209-14.

PMid:2403724

5. Badria L, Amarin Z, Jaradat A, Zahawi H, Gharaibeh A, Zobi A. Full-term viable abdominal pregnancy: a case report and review. Arch Gynaecol Obstet. 2003; 268: 340.

https://doi.org/10.1007/s00404-002-0363-y

PMid: 14504884

6. Cotlar AM. Extrauterine pregnancy: a historical review(3). Curr Surg. 2000; 57 (5): 484-492.

https://doi.org/10.1016/S0149-7944(00)00328-7

7. Sharma S, Pathak N, Goraya SPS, Mohan P. Broad ligament ectopic pregnancy. Srilanka Journal of obstetrics and gynaecology. 2011; 33: 60-2.

8. Phupong V, Lertkhachonsuk R, Triratanachat S, Sueblinvong T. Pregnancy in the broad ligament. Arch Gynecol Obstet. 2003; 268: 233-5.

https://doi.org/10.1007/s00404-002-0352-1

PMid:12942257

9. Vierhout ME, Wallenburg HC. Intraligamentary pregnancy resulting in a live infant. Am J Obstet Gynecol. 1985; 152: 878-879.

https://doi.org/10.1016/S0002-9378(85)80081-8

10. Sheela CN, Mhaskar A, Karanth S. Advanced intraligamentary pregnancy resulting in a live birth. J Obstet Gynecol India. 2011; 57: 548-549.

11. Singh U, Singh N, Sankhwar P. Full-term viable broad ligament pregnancy surgically managed with favorable feto-maternal outcome. J Obstet Gynecol India. 2012; 62: 23-24.

https://doi.org/10.1007/s13224-013-0385-3

PMid:24293863 PMCid:PMC3632680

12. Akhtar N. Ectopic pregnancy and full term live birth: a case report. J Postgrad Med Inst. 2011; 25: 181-182.

13. Vierhout ME, Wallenburg HC. Intraligamentary pregnancy resulting in a live infant. Am J Obstet Gynecol. 1985; 152: 878-9.

https://doi.org/10.1016/S0002-9378(85)80081-8

14. Damario MA, Rock JA. Ectopic pregnancy. In: Rock JA, Jones HW, editors. Te Linde's operative gynaecology. 3rd ed. Philadelphia, PA: Lippincott Williams \& Wilkins; 2008: 798-842.

15. Atrash HK, Friede A, Hogue CJR. Abdominal pregnancy in the United States: frequency and maternal mortality. Obstet Gynecol. 1987; 69: 333-337.

PMid:3822281 
16. Atrash HK, Friede A, Hogue CJR. Abdominal pregnancy in the United States: frequency and maternal mortality. Obstet Gynecol. 1987;69: 333-337.

PMid:3822281

17. Cordero DR, Adra A, Yasin S, O'Sullivan MJ. Intraligamentary pregnancy. Obstet Gynecol Surv. 1994; 49: 206.

https://doi.org/10.1097/00006254-199403000-00026

PMid:8164915

18. Desai BR, Patted Shobhana S, Pujar Yeshita V, Ruge J. Advanced secondary abdominal pregnancy following rupture of rudimentary horn. J Obstet Gynecol India. 2005; 55(2): 180 .

19. Sandberg EC, Pelligra R. The medical antigravity suit for management of surgically uncontrollable bleeding with abdominal pregnancy. Am J Obstet Gynecol. 1983;146: $519-525$.

https://doi.org/10.1016/0002-9378(83)90793-7

20. Costa SD, Presley J, Bastert G. Advanced abdominal pregnancy. Obstet Gynecol Surv. 1991; 46(8): 515-525.

https://doi.org/10.1097/00006254-199108000-00003

PMid:1886705

21. Rudra S, Gupta S, Taneja BK, Gupta R. Full term broad ligament pregnancy through a Cesarean scar. Obstet Gynecol Sci. 2013; 56(6): 404-7.

https://doi.org/10.5468/ogs.2013.56.6.404

\section{PMid:24396820 PMCid:PMC3859019}

22. Matovelo D, Ng'walida N. Hemoperitoneum in advanced abdominal pregnancy with a live baby: a case report. BMC Research Notes. 2014; 7: 106.

https://doi.org/10.1186/1756-0500-7-106

PMid:24564927 PMCid:PMC3936837

23. Pisarka MD, Casson PR, Moise KJ Jr, Di Maio DJ, Buster JE, Carson SA. Heterotropic abdominal pregnancy treated at laparoscopy. Fertil Steril.1998; 70: 159-60.

https://doi.org/10.1016/S0015-0282(98)00104-6

24. Jianping Z, Fen L, Qiu S. Full-Term Abdominal Pregnancy. A Case Report and Review of the Literature. Gynecol Obstet Invest. 2008; 65(2):139-141.

https://doi.org/10.1159/000110015

PMid:17957101

25. Teng H, Kumar G, Ramli N. A viable secondary intra-abdominal pregnancy resulting from rupture of uterine scar: role of MRI. Br J Radiol. 2007; 80: 134-136.

https://doi.org/10.1259/bjr/67136731

\section{PMid: 17704308}

26. Kun K, Wong P, Ho M, Tai C. Abdominal pregnancy presenting as a missed abortion at 16 weeks gestation. Hong Kong Med J. 2000; 6(4): 425-427.

PMid:11177167 